\title{
SPOTLIGHT INTRODUCTION
}

\section{Introduction to 'Spotlight on myeloproliferative neoplasms'}

Leukemia (2008) 22, 2; doi:10.1038/sj.leu.2405046

I was very anxious in May 2007 when I first contacted Stefan Constantinescu and Ayalew Tefferi and suggested to them to participate in a Spotlight series on myeloproliferative disorders (now called myeloproliferative neoplasms). I say anxious because I had a sense of urgency namely that time was running short on me as the responsible Editor-in-Chief of Leukemia and perhaps the bulk of the new and exciting data, would already become obsolete!

All three of us, in fact, understood the need to be very rapid, without forgetting the thoroughness, which is a quality of the Spotlights of Leukemia.

I am therefore very indebted to both Section Editors, Dr Tefferi and Dr Constantinescu, to have, at a rapid pace, sketched and completed a full program for what I believe will be a major and actual spotlight. The Editorial, which inaugurates the January issue in 2008 and which is signed by both of them, is very elegant and covers masterly all the most up-to-date steps to come.

As some of you know, Spotlights are published as soon as a review is ready. However, we will endeavor to put together as many reviews as possible when we, hopefully, receive most of them within the month of January. I can promise that we will not relent in having the reviews properly but quickly refereed.

I thank all those who contributed to this issue.

CN Muller-Berat Killmann, MD, PhD, Editor-in-Chief Leukemia, Paris, France E-mail: leukemia@leukemianature.com 